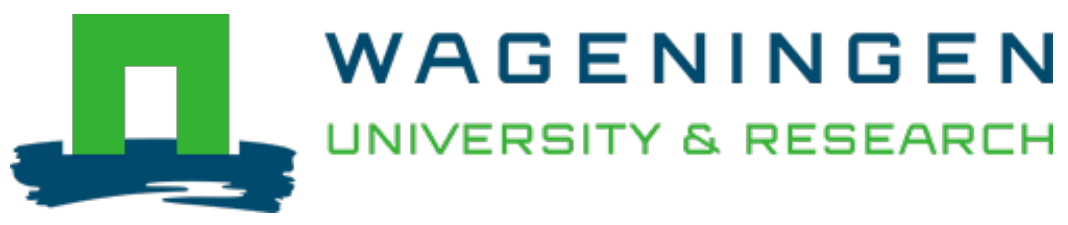

\title{
Low Gluten and Coeliac-Safe Wheat through Gene Editing
}

Plant Biotechnology

Gilissen, L.J.W.J.; Smulders, M.J.M.

https://doi.org/10.1007/978-3-030-68345-0_16

This article is made publicly available in the institutional repository of Wageningen University and Research, under the terms of article $25 \mathrm{fa}$ of the Dutch Copyright Act, also known as the Amendment Taverne. This has been done with explicit consent by the author.

Article 25 fa states that the author of a short scientific work funded either wholly or partially by Dutch public funds is entitled to make that work publicly available for no consideration following a reasonable period of time after the work was first published, provided that clear reference is made to the source of the first publication of the work.

This publication is distributed under The Association of Universities in the Netherlands (VSNU) 'Article $25 \mathrm{fa}$ implementation' project. In this project research outputs of researchers employed by Dutch Universities that comply with the legal requirements of Article $25 \mathrm{fa}$ of the Dutch Copyright Act are distributed online and free of cost or other barriers in institutional repositories. Research outputs are distributed six months after their first online publication in the original published version and with proper attribution to the source of the original publication.

You are permitted to download and use the publication for personal purposes. All rights remain with the author(s) and / or copyright owner(s) of this work. Any use of the publication or parts of it other than authorised under article $25 \mathrm{fa}$ of the Dutch Copyright act is prohibited. Wageningen University \& Research and the author(s) of this publication shall not be held responsible or liable for any damages resulting from your (re)use of this publication.

For questions regarding the public availability of this article please contact openscience.library@wur.nl 


\title{
Chapter 16 \\ Low Gluten and Coeliac-Safe Wheat Through Gene Editing
}

\author{
Luud J. W. J. Gilissen and Marinus J. M. Smulders
}

\begin{abstract}
Cereal consumption by humans is older than agriculture. During preceding eras, humans gradually acquired the necessary knowledge and tools for processing and cultivation of cereals, making themselves unconsciously prepared to become the first farmers when climate improved at the end of the last Ice Age, some 12 thousand years ago, in the Near East (Fertile Crescent) region. Early wheat cultivation in fields surrounded by wild relatives facilitated the occurrence of interspecific hybridizations; one of the resulting hybrids was bread wheat, with superior nutritional and food-technological qualities, largely due to the favourable composition of the gluten proteins in the grain. Bread wheat developed from that time into the commodity crop that it is nowadays.

Wheat-based foods and food with wheat ingredients can provoke coeliac disease in genetically predisposed susceptible individuals representing 1-2\% of the population. Some specific digestion-stable fragments of wheat gluten are recognized by immune cells that become inflammatory in the small intestine, ultimately resulting in a variety of severe symptoms. The large number of gluten genes in wheat's complex genome hinder conventional breeding to produce a coeliac-safe wheat while maintaining good baking properties, although low gluten levels can be reached. CRISPR/Cas9 enables now to produce wheat line that potentially have a strongly reduced coeliacimmunogenicity, as will be explained from two model studies. An efficient screening pipeline to detect and select promising coeliac-safe(r) wheat lines will be described. Legal and societal aspects regarding the (non) GMO status of gene-edited plants, gluten-free food production chain management, and food labelling will be discussed.
\end{abstract}

Keywords Neolithic farming $\cdot$ Hybrid wheat plants $\cdot$ Polyploid $\cdot$ Gluten • Gliadin $\cdot$ Epitope $\cdot$ Advanced wheat breeding $\cdot$ Mutagenesis $\cdot$ Screening pipeline $\cdot$ Gene editing $\cdot$ GM $\cdot$ Gluten-free $\cdot$ Legislation $\cdot$ Genomic techniques $\cdot$ CCP (critical control points)

L. J. W. J. Gilissen · M. J. M. Smulders (凶)

Plant Breeding, Wageningen University \& Research, Wageningen, The Netherlands

e-mail: rene.smulders@wur.nl

L. J. W. J. Gilissen

e-mail: luud.gilissen@wur.nl

(C) The Author(s), under exclusive license to Springer Nature Switzerland AG 2021 


\subsection{Wheat}

\subsubsection{History}

The plant family Triticeae and the genus Homo share a long history that started several million years ago in East Africa when early humanoids gradually changed their lifestyle and moved from the forest into the savannah. There, grasses grew with ungulates feeding upon. The humanoids preferred both as food, as is reflected in fossil tooth enamel. It was some two million years ago that several populations of Homo species started to leave Africa in sequential waves. First, Homo erectus, who spread eastward over Asia. Then, Homo neanderthalensis went westward into the European peninsula and lived there between 0.5 million and 30 thousand years ago. More recently, about 100,000 years ago, Homo sapiens followed its predecessors. All travelled via the Near East, where $H$. neanderthalensis and $H$. sapiens not only shared the habitat for many millennia, but also generated progeny together. However, the reason that this Near East area is also known as the Fertile Crescent relates specifically to the wide variety of plant (several cereals and pulses) and animal (several ungulates) species that were abundantly present there and formed a complete food package. Evidently, H. neanderthalensis consumed various plants as food, including Triticeae seeds, already 50 thousand years ago. Remarkably, starch grain identification on their skeletal dental calculus revealed that their cereal food was cooked before consumption. Cereal seed processing is also known from $H$. sapiens living in SouthItaly 32 thousand years ago: collected oat grains appeared to have been heated before milling, as was shown by an analysis of remaining starch grains from the surface of an excavated grinding stone. At the same time, the Cro-Magnons, known as hunters from their famous grotto paintings, made first steps towards horticulture by using tools to prepare the soil for plant cultivation. They brought plants to their living place: domestication. Further, a large camp site from almost 20 millennia ago has been excavated in the Fertile Crescent area; people lived there for twelve hundred years on a two-hectare area. Together, these facts demonstrate that during a long history Homo acquired necessary knowledge and tools, cultivation and processing technologies, and cultural practices to generate a new view on food and living. It is not surprising, therefore, that when twelve thousand years ago the global climate improved, the conditions were optimum to make the first steps towards modern agriculture just in the Fertile Crescent area: the first farmers came at stage. Cereals (wheat and barley) and pulses became the founder crops; sheep, goats and aurochs were the first domesticated animals. These plant and animal species formed the Neolithic food package of the first farmers. Farming became successful and caused overpopulation, resulting in migration waves during the following four thousand years from the Fertile Crescent area over the Mediterranean Basin by seafaring colonists as well as by north-west movements of farmers over land into the European continent, together with their domesticated cattle and their crops, including several wheat species (Gilissen and Smulders 2020, and references therein). 


\subsubsection{Diversity of Wheat Species}

The genus Triticum includes several cultivated wheat species. Some of these species have originated from interspecific hybridization events in the wild, or, during early agriculture, in fields surrounded by related wild wheat species. As the genomes in such hybrids do not pair correctly during meiosis, the hybrids are sterile, but fertility can often be restored by spontaneous chromosome doubling. This, then, gives rise to new, allopolyploid species, i.e. with multiple sets of chromosomes originating from the original wheat species.

The individual genomes of the wheat hybrids are indicated with letters A, B, C, D etc. Some of the wild wheat species are traditionally classified under the genus name Aegilops. They can hybridize with cultivated wheat (the genus Triticum). In modern wheat breeding, the hybridization potential of different wheat species is still applied to produce artificial hybrids in which desired traits such as disease resistances are transferred from one species to the other. Artificial hybrids can be produced from species of different genera: Tritordeum (wheat $\times$ barley) and Triticale (wheat $\times$ rye) are well-known examples of recently created novel hybrid species that are currently cultivated.

Seeds of wild einkorn (Triticum monococcum, a diploid wheat species with the AA genome) and wild emmer (T. turgidum, a tetraploid species with the AABB genome) were already collected by humans for food before the onset of agriculture. These became the first cereal crops because of their high domestication potential. Domestication is de facto a mutualistically beneficial relationship. Regarding wheat, it includes a gradual process of natural and steady selection starting from heterogeneous (wild) plant populations into crop types with improved agricultural and food-quality traits. Regarding wheat, such traits that were initially selected for by early farmers, consciously and unconsciously, included larger grains, a non-brittle rachis (leaving the intact ear on the plant), and naked grains (also called 'free-threshing'), which enables the grains to separate easily from the chaff, free from the hulling glumes. This characteristic is the result of a single point mutation in the DNA changing the recessive $q$ gene into dominant $Q$. This natural mutation occurred only once in the evolution of a tetraploid wheat species, and was transferred into hexaploid wheat species through hybridization and further introgression (that is the movement of a gene from one species into the gene pool of another species by repeated backcrossing of an interspecific hybrid with one of the parent species) (Matsuoka 2011).

The common bread wheat (T. aestivum, a hexaploid wheat species with the AABBDD genome) originated as a new hybrid species probably during early times of agricultural practice near the Caspian Sea. In this region, many wild Aegilops species are native. There, a cultivated free-threshing tetraploid wheat (AABB) in an agricultural field will have been hybridized with a local wild diploid Aegilops tauschii with its DD genome, which led to the hexaploid species T. aestivum. For centuries bread wheat was cultivated as part of a mixture with the tetraploid emmer and durum wheat (the latter had evolved from a free-threshing tetraploid wheat during ongoing domestication). It was only in Roman times that the milling technology was sufficiently 
advanced to produce fine flour from bread wheat enabling to bake a high-volume bread with a light crumb, superior to the flat pancake-like and compact breads from other wheat species and related grains such as rye and barley. Roman bread bakers commanded great respect from emperors and other wealthy people.

Presently, next to the diploid einkorn, eight tetraploid T. turgidum subspecies and five hexaploid T. aestivum subspecies are being cultivated, but almost $95 \%$ of the world's volume of 700-750 million metric tons is bread wheat (T. aestivum ssp aestivum); durum wheat (T. turgidum ssp. durum), used for pasta, makes up five per cent. In comparison, the other species (including the increasingly appreciated spelt wheat, T. aestivum ssp. spelta) are marginal crops.

Economically, world grain prices follow the current price of wheat. Why has especially bread wheat (and durum wheat to a lesser extent) become so popular? That is mainly because it contains a highly versatile protein component: Gluten.

\subsection{Wheat Gluten}

\subsubsection{Complexity}

A wheat grain contains three major parts, the bran (the outer layers of the grain), the germ (embryo) and the endosperm tissue containing starch and proteins (mainly gluten) as storage material that will support the seedling during the first growing phase after germination through rapid breakdown into glucose (for energy) and amino acids (to build new proteins from). Similar gluten proteins are also produced in barley and rye grains.

Gluten proteins belong to the protein superfamily of the prolamins. Wheat gluten are very diverse and comprise three protein classes (Table 16.1; Goryunova et al. 2012; Huo et al. 2018a, b; Shewry 2019; Altenbach et al. 2020):

1. HMW-glutenins of $65-90 \mathrm{kDa}$, which make up 6-10\% of the total gluten fraction; the coding genes are located on the long arms of the homoeologous chromosomes 1 (1A, 1B, 1D);

Table 16.1 Gluten genes found in the genome of variety Chinese Spring

\begin{tabular}{l|l|l|l|l|l}
\hline Gluten family & A genome & B genome & D genome & Total & Expressed \\
\hline HMW-glutenins & 2 & 2 & 2 & 6 & 4 \\
\hline LMW-glutenins & 3 & 5 & 7 & 17 & 10 \\
\hline Alpha-gliadins & 26 & 11 & 10 & 47 & 28 \\
\hline Gamma-gliadins & 4 & 6 & 4 & 14 & 11 \\
\hline Delta-gliadins & 2 & 1 & 2 & 5 & 2 \\
\hline Omega-gliadins & 4 & 7 & 6 & 17 & 11 \\
\hline
\end{tabular}

Based on Huo et al. 2018a, b 
2. sulphur-rich alpha- and gamma-gliadins and B- and C-type LMW glutenins of $30-45 \mathrm{kDa}$, taking $70-80 \%$ of the total gluten fraction; also a minor group, the delta-gliadins, can be distinguished; the coding genes are located in clusters on the short arms of the chromosomes 1 , except for the alpha-gliadin genes, which are located in tandem on the short arms of the chromosomes 6;

3. sulphur-poor omega-gliadins and D-type LMW-glutenin subunits of 30-75 kDa, representing $10-20 \%$ of the total gluten fraction, with their genes located on the short arms of the chromosomes 1.

Evolutionary, the gamma-gliadins are considered the oldest of the gliadin family. DNA sequence analysis revealed early duplications of the original gamma-gliadin gene, followed by further mutations, new duplications, pseudogenisations and deletions.

A single bread wheat variety genome (e.g. from the variety Chinese Spring) may contain as many as $\sim 100$ different gluten genes of which about sixty are expressed into proteins, as was shown by mass spectrometry analysis (Huo et al. 2018a, b; Shewry 2019; Altenbach et al. 2020; Table 16.1). Comparing different wheat varieties, variation exists in the number of expressed gluten genes, in the sequences of the encoded proteins, and in the amount of produced protein per gene. Additional variation in the gluten composition (quantitatively and qualitatively) is induced by environmental factors in the field during the growing season, such as the temperature during certain stages of crop development, and nutrient availability from the soil, in particular nitrogen and sulphur (Shewry 2019).

\subsubsection{Versatility and Functionality of Gluten in Food Products}

Gluten proteins are water-insoluble. After milling of the kernel and adding a certain, limited volume of water to the flour, its gluten together with the starch can form a dough. The elastic network of the dough is made up by the glutenins, while the gliadins provide viscosity to it. The quality of the glutenins thus determines the rheological characteristics of the dough and baking quality. The role of gliadins is supportive. Other gluten-related wheat prolamins may additionally contribute to some extent to baking quality: of these, the alpha-amylase/trypsin inhibitors (ATIs), the farinins, the purinins and the grain softness protein (GSP) have some relevance in pasta-making, dough mixing, viscosity and milling, respectively (Shewry 2019).

The overall baking quality of an individual wheat variety is determined by its total gluten quantity and its gluten quality, especially that of the HMW subunits fraction, and by the gliadin/glutenin ratio. These factors determine for which type of application a wheat variety is most suitable: for bread, cookies, or pasta. To guarantee and standardize the baking quality of flour, even though multiple varieties are cultivated and the growing conditions also vary strongly from year to year, several batches of grains from different locations, consisting of different varieties, are mixed 
in quantities such that the desired quality of the flour for a specific application is obtained. A lower gluten content in one variety will thus be compensated for by mixing with a variety with a higher gluten content from another region in the country, the continent or the world. Wheat is a commodity with a high travel standard.

Washing the dough with an excess of water will remove the starch, leaving a rubbery mass of gluten proteins, called vital wheat gluten (VWG). Extra VWG added to a dough will increase the volume of the bread. VWG can be added to flour to improve the rheological and technical properties to the specific levels of dough quality required by the baking industry for the production of a large range of different products: steam buns, toasted breads, crusty breads, sweetbreads, leavened and laminated sweet goods, laminated puff pastries, rolls and buns, crackers, cookies, sponge cakes, wafers, snacks, etc. The consumption of these products has increased during the last decades and has become an integrated part of the 'western lifestyle' (Igrejas and Branlard 2020). Accordingly, the intake of VWG has tripled since 1977 from 0.37 to $1.22 \mathrm{~g}$ per capita per day; this is a modest addition to the $\sim 15 \mathrm{~g}$ of total daily gluten consumption per capita from bread (Kasarda 2013).

Wheat flour and wheat-derived ingredients (wheat starch, wheat glucose syrup, and VWG) are applied in many more food products than in bakery alone and can be found in highly processed foods such as sweets, frozen meals, packed soups and chips, and more unexpectedly in vinegars, popcorns, gourmet products, vitamins, ice-creams, coffee, nuts, rice crackers, soy sauce, canned vegetables, cheeses, sea foods, etc. Wheat ingredients were detected in $29.5 \%$ of 10,235 labelled food items in the supermarket (Atchison et al. 2010). Declaration on the product label of the origin of e.g. the glucose syrup is not always adequate. The presence of such additives or ingredients is no issue to healthy individuals, but it may make life complex and health-impairing to susceptible persons suffering from wheat-related diseases.

\subsection{Human Health}

\subsubsection{Positive Effects of Wheat Consumption}

The consumption of healthy foods may increase life expectancy and well-being, and it may help to substantially reduce health care costs. Whole grain wheat fits in the category of healthy foods. Whole grain foods contain the three main parts of the grain: the bran (rich in fibres), the starchy endosperm (rich in carbohydrates and proteins) and the germ (rich in vitamins and micronutrients). Several large cohort studies have clearly shown that consumption (the more the better) of whole grain products (including whole grain wheat) significantly reduces the risk of several 'western lifestyle'-related chronic diseases, including obesity and diabetes, heart and vascular diseases, immune-related diseases, and several forms of cancer. Governmental agencies of many countries therefore advise to consume whole grain foods (Gilissen and Van den Broeck 2018, and references therein). 


\subsubsection{Negative Effects of Wheat Consumption}

Next to the nutritional and health benefits for all consumers, wheat may also cause allergic and intolerance reactions in certain people (Gilissen et al. 2014). True wheat allergies, mainly occurring in children, are relatively rare, with a prevalence of $0.25 \%$. Another condition, called wheat or gluten sensitivity (more specifically 'non-coeliac wheat/gluten sensitivity', NCWGS) is not well understood. It has a self-diagnosed prevalence of $\sim 10 \%$ and a medically estimated prevalence of $1 \%$. The symptoms are generally mild. The causal food compounds are not yet determined, but gluten or wheat alone is not likely. In contrast, coeliac disease (CD), a chronic inflammation of the small intestine induced by the consumption of gluten proteins from wheat, barley and rye, has been elucidated largely after decades of thorough scientific studies. Genetic factors from both the plant (knowledge on coeliac-immunogenic gluten fragments, the epitopes) and human (composition of specific receptor proteins on immune system-related T cells) have been determined. CD has a prevalence of 1$2 \%$ of the general population worldwide, which means that in the EU alone at least 4.5 million people suffer from this disease.

In the absence of a cure for $\mathrm{CD}$, prevention by following a strict, life-long glutenfree diet is the only remedy currently available. In practice this is a challenge for CD patients because of the presence of wheat and gluten in many food products as explained above (Gilissen et al. 2014; Rustgi et al. 2020). Indeed, compliance with the gluten-free diet is difficult and presently far from 100\% (Scherf et al. 2020). Extensive research has led to EU regulation EC828/2014 stating that gluten-free products should not contain gluten above the $20 \mathrm{ppm}$ threshold. This has raised interest in the development of food processing and breeding strategies for coeliacsafe and healthy wheat products (Jouanin et al. 2018a). Extensive knowledge gained during the last twenty years on the aetiology and on the causative gluten epitopes appeared helpful in such strategies. On the other hand, the development and marketing of gluten-free products (including many bakery products) has generated a billion euro/dollar market, not only for coeliac patients: gluten-free consumption has become a trend for several other (true or supposed) reasons.

\subsubsection{Coeliac Disease Epitopes}

Relevant for coeliac disease are two features of gluten proteins: they are rich in glutamine $(\mathrm{Q})$ and proline $(\mathrm{P})$ amino acids; and they contain protein domains that are repetitions of short sequences rich in these amino acids. Especially the high abundance of these two amino acids make gluten proteins partly resistant to the digestive proteases in the mouth, the stomach and the small intestine. This means that relatively long peptides can survive in the small intestine. In genetically predisposed individuals, certain fragments (containing a core sequence of nine amino acids, the so-called epitopes) may be recognized and bound by the HLA-DQ receptors 
HLA-DQ2 (notably HLA-DQ2.5) or HLA-DQ8, present on specific immune cells, the $\mathrm{CD}^{+} \mathrm{T}$-cells, that then become activated. This activation leads to cascade of cellular and molecular immune reactions ultimately resulting in an inflammation of the intestinal mucosa causing degeneration of the villi (flattening) of the small intestine surface with serious consequences for adequate uptake of nutrients, minerals and vitamins. This disturbed food uptake leads to a variety of symptoms, ranging from bowel disorders to skin, bone, nerve, and muscle problems. Because of the variety of symptoms, the majority of the patients have not yet been (properly) diagnosed.

In wheat, three alpha-gliadin, eight gamma-gliadin, two omega-gliadin and glutenin epitopes have been detected related to HLA-DQ2.5 recognition. Next to these, four minor epitopes (one from alpha-gliadin, two from gamma-gliadin and one from glutenin) with a different T-cell recognition pattern, related to HLA-DQ8, have been identified (Sollid et al. 2012, 2020). Some gluten proteins may contain multiple (up to six, in case of the alpha-gliadin 33-mer peptide) overlapping epitopes. Importantly, all CD-immunogenic epitopes contain one or more glutamic acid (E) residues, whose charge is necessary for increased affinity (recognition) by the T-cell receptor. Several of these E residues are not present in the original gluten fragment but are formed in the intestine by deamidation of glutamine (Q) into glutamic acid (E) through tissue transglutaminase-2 (TG2), an enzyme naturally present in the human intestine. For example, the DQ2.5-glia-alpha 1a epitope has the amino acid sequence PFPQPQLPY in the natural alpha-gliadin protein, but it becomes immunogenically active only after deamidation of $Q$ at amino acid position 6 into PFPQPELPY. More details of important epitopes are shown in Box 1.

\section{Box 1 Dominant Epitopes}

Most patients respond to multiple gluten epitopes. Some epitopes, listed below, are very frequently found (dominant epitopes) in HLA-DQ2.5 and HLA-DQ8 positive patients. Note the general presence of proline $(\mathrm{P})$ at the amino acid positions one and eight in the DQ2.5 epitopes. For deamidation of Q into E by TG2, a QxP residue sequence is the optimum target site (Tye-Din et al. 2010; Sollid et al. 2012, 2020; Salentijn et al. 2012); these Q residues are bold and underlined.

DQ2.5-glia-alpha 1a: PFPQPQLPY.

DQ2.5-glia-alpha 1b: PYPQPQLPY.

DQ2.5-glia-alpha 2: PQPQLPYPQ (the most common epitope).

DQ2.5-glia-alpha 33-mer: LQLQPFPQPQLPYPQPQLPYPQPQLPYPQPQPF (six overlapping epitopes; also shorter versions [19-mer; 26-mer] of this 33-mer are known).

DQ2.5-glia-gamma 1: PQQSFPQQQ (seven other gamma-epitopes are distinguished but these appear less responsive). 
DQ2.5-glia-gamma 26-mer: FLQPQQPFPQQPQQPYPQQQPQQPFPQ (five overlapping epitopes).

DQ2.5-glia-omega 1: PFPQPQQPF.

DQ2.5-glia-omega 2: PQPQQPFPW.

DQ8-glia-alpha 1: QGSFQPSQQ.

\subsection{Wheat Breeding}

\subsubsection{Aims}

Wheat is a self-pollinating crop. Farmers can cultivate it by sowing seed material saved from the preceding year. Initially, cultivation practice applied mixtures of tetraploid and hexaploid genotypes. Through conscious or unconscious selection of spontaneous mutants, landraces gradually adapted to local environmental conditions, but there is a limit to the improvement of end-use quality that can be achieved in that way. Since the early twentieth century, genetics has been used in professional wheat breeding, including pure line selection and targeted breeding. Breeders are always interested in new genetic variation. This can be achieved through introgression (trait transfer through hybridization followed by back-crossing) from other wheat species, but this process also introduces many undesired traits that subsequently have to be selected against. Alternatively, genetic variation can be induced within a cultivar through the application of mutagenic chemicals or ionizing irradiation (mutation breeding).

In wheat breeding, the main focus was traditionally directed on yield and quality trait improvements. This has culminated in the 1960s in the Green Revolution through the introduction of dwarf genes. The dwarf genes (actually, dwarfing mutations) reduce energy investment in vegetative growth (stalks), and increase grain yield. These new varieties were highly recognized worldwide. Today's breeding aims still include yield (especially starch quantity) and gluten and starch quality (for improved milling and baking quality). Adaptations to the biotic and abiotic environment, such as disease resistance genes, are receiving increasingly more attention because of the spread of major diseases and the threats of climate change, e.g. increased drought. 


\subsubsection{Coeliac-Safe Wheat}

Recently, a new goal has appeared for wheat breeding: removal of coeliac immunogenicity. This means the selection and development of wheat lines with fewer gluten genes (especially gliadin genes) and/or with gluten genes without intact immunogenic coeliac epitopes. Maintenance of food-industrial quality (milling and baking/bread quality) and good field performance are prerequisites.

Both gliadins and glutenins contain immunogenic epitopes within their protein sequences that trigger $\mathrm{CD}$, but the gliadins contain the highest numbers of the immunogenic epitopes including the most dominant ones. On a positive note, the gliadins are only of secondary importance for food-industrial quality compared with the glutenins. They may be partly omitted or replaced by other proteins to a certain extent while retaining food technological properties (Van den Broeck et al. 2011). However, only a few natural alpha-gliadin genes, notably those on chromosome 6B, are free from immunogenic epitopes. Also, although wheat varieties and species have been identified with reduced immunogenicity, the reduction is largely insufficient to be safe to coeliac patients. As the amount of gluten in wheat flour is $\sim 7 \%$, equalling 70,000 ppm (pers. comm. Johan de Meester, Cargill) and as these gluten proteins are encoded by large gene families located at different sites in the wheat genome, no classical breeding or food processing strategies have been developed yet that produce wheat-based food products approaching safety for coeliac patients at all (i.e., containing less than 20 ppm gluten). However, this may change with recently developed advanced breeding technologies (Jouanin et al. 2018a).

\subsubsection{Removing or Silencing Gluten Genes}

Using chemical treatments such as ethyl-methane sulfonate (EMS) or ionizing irradiation, random mutations can be generated in the plant genome. Radiation-induced wheat deletion lines have been produced in the 1960s that lack complete sets of genes, e.g., the alpha-gliadin locus on chromosome 6D with many coeliac-immunogenic epitopes (Van den Broeck et al. 2009). Such lines could be used as a start of a targeted breeding program, but crossing with other deletion lines often results in lethality making deletion lines less useful for this purpose. The strategy of combining deletions has, however, successfully been used in the development of ultra-low gluten barley (Tanner et al. 2016), supported by the fact that barley is a diploid crop species and gluten in barley is not relevant for the quality of beer. EMS mutation breeding can generate large numbers of random mutations and could be applied to mutate gliadin genes, but it would be very resource-intensive to trace and combine mutations in multiple genes, from many plants, into one single, coeliac-safe and well-performing wheat plant (Jouanin et al. 2018a). A clear need for a more sophisticated approaches remains. 
Two modern biotechnological approaches have recently been developed that may provide a tool towards producing wheat that is safe for CD patients: RNA interference (RNAi) and CRISPR/Cas9 gene editing. RNA interference is, as the term implies, a system to interfere with the production of, in this case, gluten proteins through their RNA transcripts, even though the DNA still contains the intact genes. A single RNAi construct can be designed for a conserved region that is common for many gluten genes. With expression of such a construct in transformed wheat lines, up to $92 \%$ reduction of the gliadins, and a 10-100 fold reduction of epitopes as detected in T-cell tests were achieved (Gil-Humanes et al. 2010). Similarly, the expression of twenty $\alpha$-gliadin genes was decreased although the expression of other storage proteins increased (Becker et al. 2012). In another approach, induced expression of the DEMETER gene, preventing changes in DNA methylation, repressed gliadin as well as glutenin gene expression in the endosperm (Wen et al. 2012). Some of the wheat lines with reduced immunogenicity but with the baking quality largely intact (Gil-Humanes et al. 2014) are sufficiently low in gliadins that food challenge trials with consumers are being planned.

RNAi requires stable genetic modification (GM) of the construct into wheat to silence the gliadins. The resulting transgenic lines therefore face expensive and time-consuming food-safety assessments for regulatory approval and consumer's acceptance, notably in the EU because of current GMO legislation.

\subsection{Gene Editing}

\subsubsection{CRISPR/Cas9 Gene Editing}

CRISPR/Cas9 ('clustered regularly interspaced short palindromic repeats and associated protein 9') has the potential to simultaneously and precisely modify multiple gliadin-encoded epitopes and/or delete (some of the) gliadin genes, while potentially maintaining food-technological quality. In CRISPR/Cas9 gene editing, a single guide RNA plus a Cas9 endonuclease is brought into embryogenic cells of a wheat cultivar. The guide RNA directs the endonuclease to the target DNA sites in gliadin genes, where it creates a double-strand break. This triggers the native DNA repair system of the cell. All living cells have extensive DNA repair mechanisms and these are continuously repairing the many spontaneous and induced mutations in the DNA. This repair system is highly accurate, but can sometimes make mistakes, and doublestrand breaks are particularly difficult to repair. Mistakes may then result in small deletions of one or a few nucleotides at the site of the break in the gliadin gene. However, in wheat, where alpha-gliadin genes are tandemly repeated, simultaneous double-strand breaks may occur in consecutive genes, and this could result in deletions of DNA fragments carrying one or more gliadin genes (Fig. 16.1). A great advantage of the CRISPR/Cas9 system is that it can be targeted simultaneously at multiple gene sequences. Important to note is that such mutations are identical 


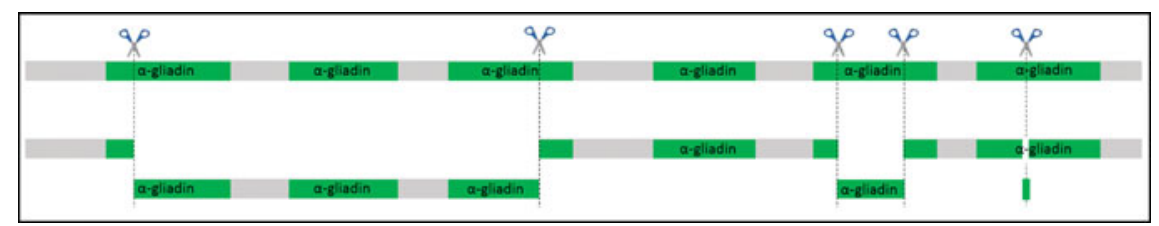

Fig. 16.1 Representation of a part of a single alpha-gliadin Gli-2 locus on wheat chromosome 6 with the various mutagenic actions that can be induced by CRISPR/Cas9 ( taken from Jouanin et al. 2019). Note that after generation of a double-strand break, the DNA repair mechanism may occasionally result in different mutation types, ranging from a point mutation, to an insertion or a deletion of nucleotides, to a deletion of a gene fragment, and a deletion of a (part of a) gene locus. A mosaic of mutations may occur in a single regenerated gene-edited plant. Mutations in genes on different chromosomes will segregate in later generations

to naturally random-occurring mutations upon double-strand breaks, but in case of CRISPR/Cas9 these mutations are at desired locations.

The next step in this process involves the regeneration of plants from the geneedited cells. These plants will be self-pollinated to enable the production and further testing of seeds with the induced (desired) targeted mutations in the gliadins. The breeder is especially interested in plants that have desired mutations but do no longer contain the construct in its genome. According to Mendel's laws, and in case a single CRISPR/Cas9 construct is present, self-pollination will result in progeny of which one quarter will be free of the CRISPR/Cas9 construct.

Recently two proof-of-concept studies have been carried out in wheat. SánchezLéon et al. (2018) targeted two conserved sites next to the epitope-containing region in 45 alpha-gliadin genes of a single wheat line. In this study, 47 plants of the progeny were confirmed as being gene-edited. In one of the resulting lines, up to 35 of the 45 genes appeared mutated, with small or larger deletions around the target sites. This line showed a $85 \%$ reduction of total gluten protein as measured with the R5 gluten quantification assay (R-Biopharm, Darmstadt), which is approved for the detection and quantification of small amounts of gluten in gluten-free products. In the other study, Jouanin et al. (2019) confirmed 117 gene-edited plants after simultaneously targeted multiple sites in alpha-gliadin and gamma-gliadin genes; indeed, mutations in both gene families in the same plant were generated.

Although targeted to gliadin genes, not all potential sites in these genes will be mutated in a single line as most repair actions will not result in a mutation. As a consequence, the progeny will consist of a population of plants that each may contain a mosaic of edited and unaffected genes, and perhaps loss of some genes. The edits on different chromosomes will segregate in next self-pollinated generations. To limit the number of individual plants to be screened, a rigorous reduction through qualitydirected selection steps is required (Fig. 16.2). This should result in a workable selection program, which aims at maintaining only the few most promising plants (genotypes) for multiplication, cultivation and eventual application in coeliac-safe(r) food (Jouanin et al. 2020). 


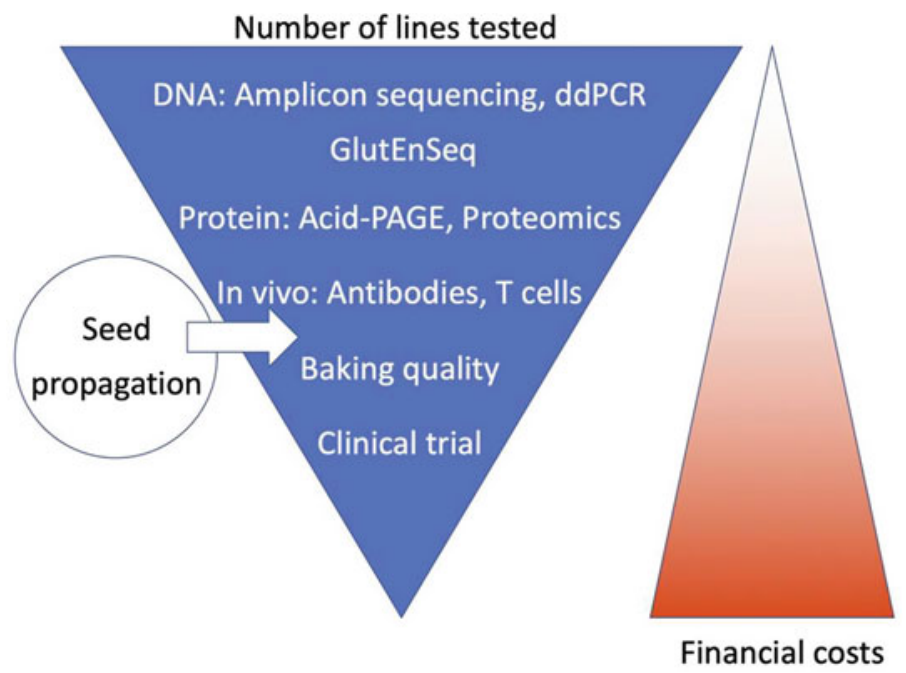

Fig. 16.2 Schematic overview of the sequential steps in the screening pipeline (from Jouanin et al. 2020). The first steps, screening at the DNA and protein level, may have to handle large numbers of plants and should therefore preferentially include fast, high throughput, and cheap methods. Subsequently, more detailed but time-consuming and expensive methods can be employed to precisely characterize a limited number of promising lines at the immunological level. The last steps include screening of food-technological quality and coeliac safety. These require sufficient amounts of grains, thus a cultivation step on the field

The use of CRISPR/Cas9-mediated gene editing in breeding thus includes two major aspects: first, a precisely defined target DNA sequence; and second, the right choice of screening technologies at the DNA and protein level, supplemented later on with screening at the phenotypic and industrial quality level, to select the most promising plant lines.

\subsection{Perspectives of Coeliac-Safe(r) Wheat}

\subsubsection{The Gluten-Free Market}

The development of safe-gluten wheat for coeliac disease patients is still a long way to go, as this really must have the equivalent of $20 \mathrm{ppm}$ gluten or less to be legally approved and labelled as 'gluten-free'. However, 'gluten-free' is worldwide becoming a billion dollar/euro market, including, next to coeliac patients, also people that want to reduce their gluten intake for supposed health reasons, or people with self-diagnosed NCW/GS. This market goes beyond the coeliac disease patients who need a strict gluten-free diet. 
Products for coeliac disease patients must be labelled as 'gluten-free' implying the maximum threshold of $20 \mathrm{ppm}$ gluten. Another legally accepted category is 'low in gluten' with a threshold of $100 \mathrm{ppm}$, for products aiming at less-sensitive people. In addition, vague marketing terms are also sometimes used, for instance the company Arcadia Biosciences now sells a "Reduced Gluten GoodWheat" variety with $65 \%$ less gluten for non-coeliac or non-wheat allergic consumers who only want to reduce the amount of gluten in their diet. Depending on the level of reduced coeliac immunogenicity that can be reached by gene editing, wheat lines and the products thereof may therefore become categorized as 'gluten-free' (when these contain an equivalent of the legally accepted $<20$ ppm gluten), 'low in gluten' ( $<100 \mathrm{ppm}$ ), or 'reduced in gluten' (an undefined category).

\subsubsection{Gene Editing Products as Non-GM}

Although the CRISPR/Cas9 edited lines produced in the pilot studies mentioned in this paper (Sanchez-Leon et al. 2018; Jouanin et al. 2020) are not yet safe for CD patients, they demonstrate the power of gene editing for modifying tens of gliadin genes at once in bread wheat. Technically, gene editing requires foreign DNA to be introduced in the plant genome, but only as a transient step in the targeted gene editing. After self-pollination, part of the offspring will not inherit the construct while they do inherit edited gliadin genes. As such, applying CRISPR/Cas9 as a biological mutagenic agent is basically identical to chemical (EMS) or physical (ionizing radiation) mutagenesis. Therefore, in many countries worldwide, geneedited plants, as a product, are considered as not GM, because its production follows the conventional breeding rules, including those of mutation breeding. However, the EU regulation is different as it follows the process instead of considering the end product. On July 25th 2018 the European Court of Justice ruled that (according to Directive 2001/18/EC) plants produced through gene editing as a mutation technique, are not exempted from GM regulation as long as it has not been "conventionally used" in "a number of applications" and have "a long safety record". This decision will have serious consequences for coeliac patients within the EU regarding the availability of gene-edited safe foods (Jouanin et al. 2018b). However, for the (coeliac) patients and their societies, the methods used to produce such safe products are irrelevant. Their concern relates to proper testing and labelling.

\subsubsection{Labelling}

Regarding labelling, the R5 assay is especially developed to quantify the gluten content, especially in gluten-free products, for food labelling purposes to inform coeliac patients at their purchase. The threshold of $20 \mathrm{ppm}$ gluten is determined by the Codex Alimentarius and legally approved internationally worldwide. However, 
the R5 assay will be useless for coeliac-safe food products derived from gene-edited wheat that still contain gluten, but these lack the coeliac-immunogenic epitopes. Such new products will require a re-evaluation of the current legislation and a matching labelling strategy, in accordance with the total quantity and quality (severity) of coeliac-immunogenic gluten epitope sequences in the product.

\subsubsection{Production Chain}

Gene-edited wheat lines should be produced in a production chain that is entirely and guaranteed separated from regular-wheat production chains. This implies separate facilities on the farms regarding the field for cultivation, the sowing seed batches, the harvest machineries, the transport and storage facilities, but also at the processing factories, regarding the production lines, packaging and labelling, and transport to the retail. All these critical points should be under strict control.

\subsection{Conclusions}

Wheat is a healthy and nutritious crop. It contains two (in durum and pasta wheat) or three (in bread wheat) different genomes, making the crop genetically highly complex. Bread wheat contains about one hundred gluten genes, many of which are expressed into proteins representing several classes of gluten. Proteins of several classes have immunogenic properties to which sensitive individuals may develop diseases, of which coeliac disease is the most common and best studied. Immunogenic responses have been linked to specific gluten fragments, mainly occurring in the gliadin proteins. The genome complexity of wheat prevents the application of conventional breeding to generate completely coeliac-safe wheat. Pilot studies clearly demonstrate the feasibility of CRISPR/Cas9 gene editing technology for the production of coeliac-safe(r) wheat plants and food products. If such products are becoming realistic for the gluten-free consumer's market, critical control points (CCPs) in the entire production chain should be clearly defined and strictly monitored, as well as the legal aspects regarding 'gluten-free' labelling be re-evaluated. On behalf of the concerning consumers, in Europe the current GMO status resulting from the use of gene editing in breeding new coeliac-safe wheat varieties should be reconsidered in agreement with the non-GMO status of such products elsewhere worldwide.

Acknowledgements The writing of this article was partially made possible by the Well on Wheat (WoW) project (https://www.um-eatwell.nl/wow/), an international research project under the umbrella of the Health Grain Forum and ICC-Vienna, addressing the effect of wheat consumption and processing on food composition changes and the related effects on gastrointestinal function and symptoms in humans. The WoW project is partially funded by the Dutch Topsector AgriFood project TKI 1601P01. The Centre of Genetic Resources, The Netherlands (CGN) is thanked for providing office space and facilities to LG. 


\section{References}

Altenbach SB, Chang H, Simon-Buss A et al (2020) Exploiting the reference genome sequence of hexaploid wheat: a proteomic study of flour proteins from the cultivar Chinese Spring. Funct Integr Genomics 20:1-16. https://doi.org/10.1007/s10142-019-00694-Z

Atchison J, Head L, Gates A (2010) Wheat as food, wheat as industrial substance; comparative geographies of transformation and mobility. Geoforum 41:236-246. https://doi.org/10.1016/j. geoforum.2009.09.006

Becker D, Wieser H, Koehler P, Folck A, Mühling KH, Zörb C (2012) Protein composition and techno-functional properties of transgenic wheat with reduced alpha-gliadin content obtained by RNA interference. J Appl Bot Food Qual 85:23-33

Directive 2001/18/EC of the European Parliament and of the Council of 12 March 2001 on the deliberate release into the environment of genetically modified organisms and repealing Council Directive 90/220/EEC - Commission Declaration. Off J L 106:0001-0039 (17/04/2001)

Gil-Humanes J, Pistón F, Tollefsen S, Sollid LM, Barro F (2010) Effective shutdown in the expression of celiac disease-related wheat gliadin T-cell epitopes by RNA interference. Proc Natl Acad Sci USA 107:17023-17028

Gil-Humanes J, Piston F, Altamirano-Fortoul R, Real A et al (2014) Reduced-gliadin wheat bread: An alternative to the gluten-free diet for consumers suffering gluten-related pathologies. PLoS ONE 9:e90898. https://doi.org/10.1371/journal.pone.0090898

Gilissen LJWJ, van der Meer IM, Smulders MJM (2014) Reducing the incidence of allergy and intolerance to cereals. J Cereal Sci 59:337-353. https://doi.org/10.1016/j.jcs.2014.01.005

Gilissen LJWJ, van den Broeck HC (2018) Breeding for healthier wheat. Cereal Foods World 63:132-136. https://doi.org/10.1094/CFW-63-4-0132

Gilissen LJWJ, Smulders MJM (2020) Biotechnological strategies for the treatment of gluten intolerance. In: Rossi M (ed) Gluten quantity and quality in wheat and in wheat-derived products. Elsevier, Amsterdam (in press)

Goryunova SV, Salentijn EMJ, Chikida NN, Kochieva EZ, van der Meer IM, Gilissen LJWJ, Smulders MJM (2012) Expansion of the gamma-gliadin gene family in Aegilops and Triticum. BMC Evol Biol 12:215. https://doi.org/10.1186/1471-2148-12-215

Huo N, Zhu T, Altenbach S, Dong L, Wang Y, Mohr T et al (2018a) Dynamic evolution of $\alpha$-gliadin prolamin gene family in homeologous genomes of hexaploid wheat. Sci Rep 8:5181. https://doi. org/10.1038/s41598-018-23570-5

Huo N, Zhang S, Zhu T, Dong L, Wang Y, Mohr T et al (2018b) Gene duplication and evolution dynamics in the homeologous regions harboring multiple prolamin and resistance gene families in hexaploid wheat. Front Plant Sci 9:673. https://doi.org/10.3389/fpls.2018.00673

Igrejas G, Branlard G (2020) The importance of wheat. In: Igrejas et al (eds) Wheat quality for improving processing and human health (Chap 1). Springer Nature, Switzerland AG, pp 1-8. https://doi.org/10.1007/978-3-030-34163-3

Jouanin A, Boyd LA, Visser RGF, Smulders MJM (2018a) Development of wheat with hypoimmunogenic gluten obstructed by the gene editing policy in Europe. Front Plant Sci 9:1523. https:// doi.org/10.3389/fpls.2018.01523

Jouanin A, Gilissen LJWJ, Boyd LA, Cockram J, Leigh FJ, Wallington EJ, van den Broeck HC, van der Meer IM, Schaart JG, Visser RGF, Smulders MJM (2018b) Food processing and breeding strategies for coeliac-safe and healthy wheat products. Food Res Int 110:11-21. https://doi.org/ 10.1016/j.foodres.2017.04.025

Jouanin A, Schaart JG, Boyd LA, Cockram J, Leigh FJ, Bates R, Wallington EJ, Visser RGF, Smulders MJM (2019) Outlook for coeliac disease patients: towards bread wheat with hypoimmunogenic gluten by gene editing of $\alpha$ - and $\gamma$-gliadin gene families. BMC Plant Biol 19:333. https://doi.org/10.1186/s12870-019-1889-5

Jouanin A, Gilissen LJWJ, Schaart JG, Leigh FJ, Cockram J, Wallington EJ, Boyd LA, Van Den Broeck HC, Van der Meer IM, America AHP, Visser RGF, Smulders MJM (2020) CRISPR/Cas9 
gene editing of gluten in wheat to reduce gluten content and exposure-reviewing methods to screen for coeliac safety. Front Nutr 7:51. https://doi.org/10.3389/fnut.2020.00051

Kasarda DD (2013) Can an increase in celiac disease be attributed to an increase in the gluten content of wheat as a consequence of wheat breeding? J Agric Food Chem 61:1155-1159. https://doi. org/10.1021/jf305122s

Matsuoka Y (2011) Evolution of polyploid Triticum wheats under cultivation: the role of domestication, natural hybridization and alloploid speciation in their diversification. Plant Cell Physiol 52:750-764. https://doi.org/10.1093/pcp/pcr/pcr018

Rustgi S, Shewry P, Brouns F (2020) Health hazards associated with wheat and gluten consumption in susceptible individuals and status of research on dietary therapies. In: Igrejas G, Ikeda T, Guzmán C (eds) Wheat quality for improving processing and human health. Springer, Cham, Switzerland, pp 471-515. https://doi.org/10.1007/978-3-030-34163-3_20

Salentijn EM, Mitea DC, Goryunova SV, van der Meer IM, Padioleau I, Gilissen LJWJ, et al. (2012) Celiac disease T-cell epitopes from gamma-gliadins: immunoreactivity depends on the genome of origin, transcript frequency, and flanking protein variation. BMC Genom 13:277. https://doi. org/10.1186/1471-2164-13-277

Sanchez-Leon S, Gil-Humanes J, Ozuna CV, Gimenez MJ, Sousa C, Voytas DF, Barro F (2018) Low-gluten, nontransgenic wheat engineered with CRISPR/Cas9. Plant Biotechnol J 16:902-910. https://doi.org/10.1111/pbi.12837

Scherf KA, Catassi C, Chirdo FG, Ciclitira PJ, Feighery C, Gianfrani C, Koning F, Lundin KEA, Schuppan D, Smulders MJM, Tranquet O, Troncone R, Koehler P (2020) Recent progress and recommendations on celiac disease from the working group on prolamin analysis and toxicity. Front Nutr 7:29. https://doi.org/10.3389/fnut.2020.00029

Shewry PR (2019) What is gluten-why is it special. Front Nutr 6:101. https://doi.org/10.3389/ fnut.2019.00101

Sollid LM, Qiao SW, Anderson RP, Gianfrani C, Koning F (2012) Nomenclature and listing of celiac disease relevant gluten T-cell epitopes restricted by HLA-DQ molecules. Immunogenetics 64:455-460. https://doi.org/10.1007/s00251-012-0599-z

Sollid LM, Tye-Din JA, Qiao SW, Anderson RP, Gianfrani C, Koning F (2020) Update 2020: nomenclature and listing of celiac disease-relevant gluten 1324 epitopes recognized by CD4+ T cells. Immunogenetics 72:85-88. https://doi.org/10.1007/s00251-019-01141-w

Tanner GJ, Blundell MJ, Colgrave ML, Howitt CA (2016) Creation of the first ultra-low gluten barley (Hordeum vulgare L.) for coeliac and gluten-intolerant populations. Plant Biotechnol J 14:1139-1150. https://doi.org/10.1111/pbi.12482

Tye-Din JA, Stewart JA, Dromey JA, Beissbarth T, van Heel DA, Tatham A, et al. (2010) Comprehensive, quantitative mapping of T cell epitopes in gluten in celiac disease. Science Transl Med 2(41):41ra51-41ra51. https://doi.org/10.1126/scitranslmed.3001012

Van den Broeck HC, van Herpen TWJM, Schuit C, Salentijn EMJ, Dekking L, Bosch D, Hamer RJ, Smulders MJM, Gilissen LJWJ, van der Meer IM (2009) Removing celiac disease-related gluten proteins from bread wheat while retaining technological properties: a study with Chinese Spring deletion lines. BMC Plant Biol 9:41. https://doi.org/10.1186/1471-2229-9-41

Van den Broeck HC, Gilissen LJWJ, Smulders MJM, van der Meer IM, Hamer RJ (2011) Dough quality of bread wheat lacking alpha-gliadins with celiac disease epitopes and addition of celiacsafe avenins to improve dough quality. J Cereal Sci 53:206-216. https://doi.org/10.1016/j.jcs. 2010.12.004

Wen S, Wen N, Pang J, Langen G, Brew-Appiah RA, Mejias JH, Osorio C, Yang M, Gemini R, Moehs CP, Zemetra RS (2012) Structural genes of wheat and barley 5-methylcytosine DNA glycosylases and their potential applications for human health. Proc Natl Acad Sci USA 109:20543-20548 
Luud J. W. J. Gilissen (Ph.D. 1978 Radboud University Nijmegen, The Netherlands) works on the health aspects of cereal and grain foods (with focus on oats and whole grains). He coinitiated the Allergy Consortium Wageningen (2001-present), the Dutch Coeliac Disease Consortium (2004-2013), the Dutch Oat Chain (2007-present), and the Well-on-Wheat project (2016present) concerning non-celiac wheat sensitivity. He is (co)author of about 120 peer-reviewed research papers and is co-editor of two books (H-index 31).

Marinus J. M. (René) Smulders is group leader and manager in Plant Breeding, Wageningen University and Research, The Netherlands. He studies genetic mapping of traits in crops with polyploid genomes, such as rose and wheat. He participates in societal discussions on opportunities of new plant breeding techniques, including gene editing, for generating crop varieties that will contribute to addressing the challenges of agriculture in the twenty-first century, and that have direct benefits for consumers, including people with coeliac disease. He is (co)author of 180 peer-reviewed research papers. 